\title{
Regulatory role of long non-coding RNA UCA1 in signaling pathways and its clinical applications (Review)
}

\author{
ZHAOPING LIU $^{1 *}$, YANYAN WANG $^{1 *}$, SHUNLING YUAN $^{1}$, FENG WEN $^{2}$, \\ JING LIU ${ }^{3}$, LIHENG ZOU ${ }^{1}$ and JI ZHANG ${ }^{1,4}$

\begin{abstract}
Departments of ${ }^{1}$ Rheumatology and ${ }^{2}$ Hematology, The First Affiliated Hospital, University of South China, Hengyang, Hunan 421001; ${ }^{3}$ Molecular Biology Research Center and Center for Medical Genetics, Shenzhen Traditional Chinese Medicine Hospital, Shenzhen, Guangdong 518033, P.R. China
\end{abstract} \\ School of Life Sciences, Central South University, Changsha, Hunan 410078; ${ }^{4}$ Department of Clinical Laboratory,
}

Received September 5, 2020; Accepted February 11, 2021

DOI: $10.3892 / 01.2021 .12665$

\begin{abstract}
Long non-coding RNA metastasis-associated urothelial carcinoma associated 1 (UCAl) plays a pivotal role in various human diseases. Its gene expression is regulated by several factors, including transcription factors, chromatin remodeling and epigenetic modification. UCAl is involved in the regulation of the PI3K/AKT, Wnt/ $\beta$-catenin, MAPK,
\end{abstract}

Correspondence to: Ms. Liheng Zou or Professor Ji Zhang, Department of Rheumatology, The First Affiliated Hospital, University of South China, 69 Chuanshan Road, Hengyang, Hunan 421001, P.R. China

E-mail: zoulhhy@126.com

E-mail: jizhang@fsyy.usc.edu.cn

${ }^{*}$ Contributed equally

Abbreviations: 5-FU, 5-fluorouracil; AML, acute myeloid leukemia; ARID1A, AT-rich interaction domain 1A; BC, breast cancer; BMP9, bone morphogenetic protein 9; $\mathrm{BRG} 1$, brahma-related gene 1; $\mathrm{C} / \mathrm{EBP} \alpha$, CCAAT/enhancer binding protein $\alpha$; CCND1, cyclin D1; CDK6, cyclin-dependent kinase 6; ceRNA, competitive endogenous RNA; CLIC1, chloride intracellular channel 1; CRC, colorectal cancer; CREB, cAMP response element-binding; CXCR4, C-X-C chemokine receptor type 4; DLL4, Delta-like 4; DN, diabetic nephropathy; EMT, epithelial-to-mesenchymal transition; EP300, E1A binding protein p300; EZH2, enhancer of zeste homolog 2; GC, gastric cancer; H/R, hypoxia/reoxygenation; $\mathrm{H} 3 \mathrm{~K} 9 \mathrm{me} 3$, histone 3 lysine 9 trimethylation; HCC, hepatocellular carcinoma; HULC, highly upregulated in liver cancer; lncRNA, long non-coding RNA; miRNA/miR, microRNA; MM, multiple myeloma; mTOR, mammalian target of rapamycin; NSCLC, non-small cell lung cancer; OGD, oxygen-glucose deprivation; ORFs, open reading frames; OS, overall survival; PC, pancreatic cancer; PD, Parkinson's disease; PD-1, programmed cell death 1; PDAC, pancreatic ductal adenocarcinoma; RAC1, RAS-related C3 botulinus toxin substrate 1; RFS, relapse-free survival; SLE, systemic lupus erythematosus; TCC, transitional cell carcinoma; TEAD, TEA domain; TGF- $\beta$, transforming growth factor- $\beta$; TNM, tumor-node-metastasis; UCA1, urothelial carcinoma associated 1; YAP, yes-associated protein

Key words: lncRNA, UCA1, signaling pathway, diagnosis, prognosis
NF- $\kappa \mathrm{B}$ and JAK/STAT signaling pathways, affecting a series of cellular biological functions, such as cell proliferation, apoptosis, migration, invasion and tumor drug resistance. Furthermore, UCA1 is used as a novel potential biomarker for disease diagnosis and prognosis, as well as a target for clinical gene therapy. The present review systematically summarizes and elucidates the mechanisms of upstream transcriptional regulation of $U C A 1$, the regulatory role of $U C A 1$ in multiple signaling pathways in the occurrence and development of several diseases, and its potential applications in clinical treatment.

\section{Contents}

1. Introduction

2. Overview of UCAI

3. Upstream regulation of $U C A I$ expression

4. Signaling pathways regulated by $U C A 1$

5. Clinical applications of UCA1

6. Conclusions and perspective

\section{Introduction}

The whole genome sequencing of eukaryotes has confirmed that $~ 93 \%$ of the DNA in the human genome can be transcribed into RNA (1). Notably, only $2 \%$ of mRNAs encode proteins and the remaining $98 \%$ are non-coding RNAs (1). Among the different types of non-coding transcripts, long non-coding RNAs (lncRNAs) have attracted great interest. lncRNAs do not contain any extended open reading frames (ORFs) and are $>200$ nucleotides in length (2). They have been identified as indispensable regulators in a variety of physiological and pathological processes, including epigenetic inheritance, cell cycle, post-transcriptional regulation, translation and chromatin modification (3). In addition, IncRNAs participate in the regulation of cell proliferation, differentiation, apoptosis, invasion, migration and tumor drug resistance (4). IncRNAs play important roles in the occurrence and development of various diseases, particularly malignant tumors $(5,6)$. Previous studies 
have demonstrated that lncRNAs function as either oncogenes or tumor suppressors, and are involved in the regulation of tumorigenesis and progression of various tumors $(5,6)$.

Urothelial carcinoma associated 1 (UCAI) was initially identified in bladder cancer by high-throughput RNA sequencing, and is associated with the progression of bladder cancer (7). UCAl has been demonstrated to be highly expressed in several human tumors, such as gastric cancer (GC) and cholangiocarcinoma, which is closely associated with tumor-node-metastasis (TNM) stage, depth of invasion, vascular invasion, lymph node metastasis, overall survival (OS) and relapse-free survival (RFS) (8-10). In addition, UCA1 is involved in regulating cell proliferation, apoptosis, migration, invasion and drug resistance (11). Several studies have reported that UCAl participates in the regulation of multiple cellular signaling pathways at transcriptional, post-transcriptional and epigenetic levels (Fig. 1) (12,13). The present review discusses the molecular mechanisms and clinical potential of UCA1 in the regulation of signaling pathways and transcription in human diseases.

\section{Overview of $U C A 1$}

In 2006, UCA 1 was demonstrated to be highly specific and sensitive in the diagnosis of bladder cancer, particularly in patients with superficial G2-G3 (7). Furthermore, UCA1 is considered to be the most specific gene for bladder transitional cell carcinoma (TCC) (7). UCAI exhibits a notable differential diagnostic function in several urinary tract diseases without TCC (7).

The UCAl gene contains three exons and two introns, and is located on the positive strand of human chromosome 19p13.12(7). Notably, the UCAl sequence contains multiple termination sequences, without any conservative long ORFs $(14,15)$. Initially, the full-length cDNA of UCAl was identified as $1.4 \mathrm{~kb}$ (7). However, recent studies have demonstrated that $U C A l$ has three different isoforms $(1.4,2.2$ and $2.7 \mathrm{~kb})(16,17)$. Currently, the $1.4 \mathrm{~kb}$ isoform has attracted great interest (14). In addition to its associations with non-cancerous diseases, including systemic lupus erythematosus (SLE), diabetic nephropathy (DN) and Parkinson's disease (PD) (18-20), UCAl is also involved in the progression of different types of cancer, including bladder cancer, colorectal cancer (CRC) and hepatocellular carcinoma (HCC) (21-23). Furthermore, overexpression of UCA1 is closely associated with clinicopathological characteristics, including poor prognostic factors, such as TNM stage, vascular invasion and lymph node metastasis $(8,24,25)$.

Increasing evidence suggest that $U C A 1$ functions as an oncogene, which plays an important role in the tumorigenesis and development of different types of cancer, including papillary thyroid carcinoma (26), pancreatic cancer (PC) (27) and lung adenocarcinoma (28). UCAl expression is regulated by several factors, such as transcription factors, chromatin remodeling and epigenetic modification (Fig. 2) (29-31). Furthermore, $U C A 1$ contains microRNA ( $\mathrm{miRNA} / \mathrm{miR}$ ) binding sites that regulate the expression of target genes through the sponging of miRNAs (Table I) $(8,11,24)$.

\section{Upstream regulation of $U C A 1$ expression}

As presented in Table II, upstream regulators of UCA1 include transcription factors, chromatin remodeling complexes, epigenetic changes and binding proteins (29,31-33). The core promoter of the UCAI gene can bind with several transcription factors, such as CCAAT/enhancer binding protein $\alpha(\mathrm{C} / \mathrm{EBP} \alpha)(32), \mathrm{C} / \mathrm{EBP} \beta$ (34), E26 transformation-specific transcription factor 2 (35), specificity protein 1 (36), MYB (37) and E1A binding protein p300 (EP300) (38). These transcription factors interact with the promoter to upregulate $U C A 1$ expression, and SND1 can upregulate $U C A 1$ expression through transcriptional activator $M Y B$ and promote 5-fluorouracil (5-FU)-induced apoptosis of HCC cells (37). Similarly, macrophage-derived chemokine CCL18 upregulates UCAI expression through transcription factor EP300 in osteosarcoma (38). In addition, the combination of hyaluronic acid and CD44 stimulates the signal transduction of $\mathrm{PI} 3 \mathrm{~K}$ and $\mathrm{AKT}$, resulting in phosphorylation of $\mathrm{C} / \mathrm{EBP} \alpha$, which binds to the promoter of the UCAl gene to induce transcriptional activation of $U C A 1$, resulting in migration and invasion of HSC-3 cells in human head and neck squamous cell cancer (39).

AT-rich interaction domain 1A (ARID1A) is one of the major members of SWItch/Sucrose non-fermentable chromatin remodeling complexes, which is often found to be loss-of-function mutations in different types of cancer, such as non-small cell lung cancer (NSCLC) (40), breast cancer (BC) (41) and pancreatic ductal adenocarcinoma (PDAC) (42). ARID1A inhibits $U C A 1$ expression by regulating chromatin access of transcription factor $\mathrm{C} / \mathrm{EBP} \alpha$ (30). It has been confirmed that the CAPER $\alpha / \mathrm{TBX} 3$ complex directly inhibits UCA1 transcription and promotes cancer cell senescence by regulating chromatin structure (43). Furthermore, the AT-rich sequence binding protein 1 suppresses $U C A l$ expression by closing the chromatin structure of the $U C A 1$ promoter region in BC (29). Notably, epigenetic modification participates in regulating $U C A 1$ expression. S-adenosylmethionine inhibits UCA1 transcription by increasing DNA methyltransferase or decreasing DNA demethylase (31). The stability of UCAI is notably improved due to the formation of functional ribonucleoprotein complexes between hnRNPI and UCA1 (44). Conversely, UCA1 interacts with insulin-like growth factor 2 mRNA-binding protein 1 and is downregulated due to its reduced stability (45).

Bone morphogenetic protein 9 (BMP9), a member of the BMP family, belongs to the transforming growth factor- $\beta$ (TGF- $\beta$ ) superfamily. TGF- $\beta$ is a well-known inducer of epithelial-to-mesenchymal transition (EMT) $(33,46)$. BMP9 or TGF- $\beta$ can upregulate $U C A 1$ expression to promote invasion and metastasis of cancer cells, including BC and GC cells $(33,46)$. In addition, TGF- $\beta$ inactivates the Hippo pathway by regulating the complex of transcriptional co-activator with PDZ binding motif/yes-associated protein (YAP) and transcriptional enhancer TEA domain (TEAD), which subsequently upregulates $U C A 1$ expression and promotes the migration and invasion of BC cells (47). Some clinical trials have reported that metformin exhibits anticancer potential and can be used as an adjuvant for cancer prevention or an AMPK activator for cancer treatment $(48,49)$. Metformin can decrease endometrial hyperplasia via the $U C A 1 / \mathrm{miR}-144 / \mathrm{TGF}-\beta 1 / \mathrm{AKT}$ signaling pathway (50). In addition, metformin suppresses the migratory ability of trophoblast cells by regulating the signal transduction pathway of $U C A 1 / \mathrm{miR}-204 / \mathrm{MMP}-9$ (51). Notably, lncRNA 
A

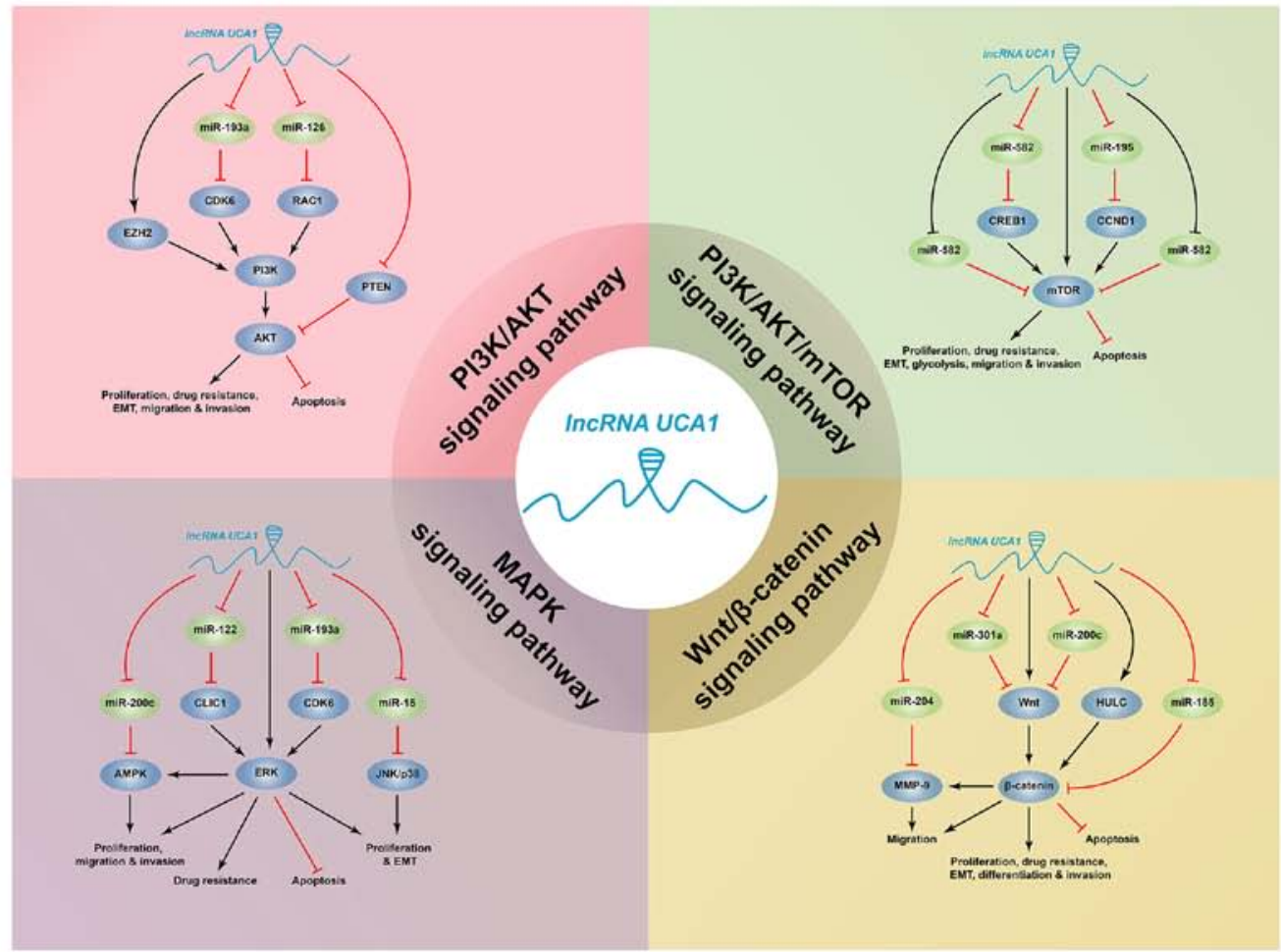

B

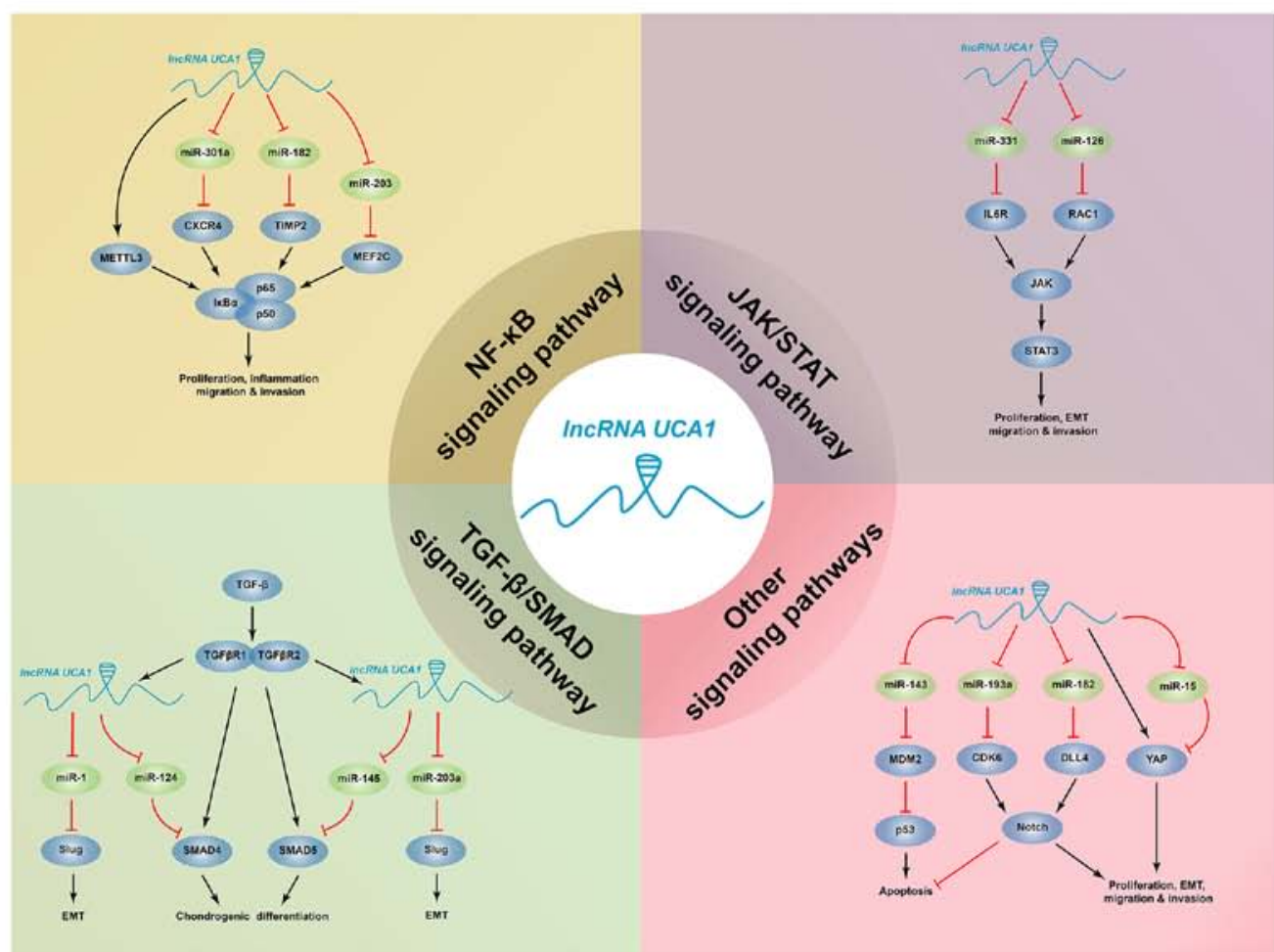

Figure 1. Signaling pathways in diseases mediated by UCA1.UCA1 regulates key signaling pathways by acting as a competitive endogenous RNA, thus affecting biological activities, such as cell proliferation, apoptosis, migration, invasion and drug resistance in cancers and non-cancerous diseases. UCA1, urothelial carcinoma associated 1; CCND1, cyclin D1; CDK6, cyclin-dependent kinase 6; CLIC1, chloride intracellular channel 1; CREB1, cAMP response element-binding protein 1; CXCR4, C-X-C chemokine receptor type 4; DLL4, Delta-like 4; EZH2, enhancer of zeste homolog 2; HULC, highly upregulated in liver cancer; MEF2C, myocyte enhancer factor 2C; METTL3, methyltransferase-like 3; MMP-9, matrix metalloproteinase-9; mTOR, mammalian target of rapamycin; RAC1, RAS-related C3 botulinus toxin substrate 1; TGF- $\beta$, transforming growth factor- $\beta$; TIMP2, tissue inhibitor of metalloproteinase-2; YAP, yes-associated protein; miR, microRNA; EMT, epithelial-to-mesenchymal transition; lncRNA, long non-coding RNA.

GAS8-AS1 inhibits migration and invasion of osteosarcoma cells by downregulating UCAl expression (52). Furthermore, up-frameshift protein 1, palmitic acid, cancer-associated fibroblasts and hepatitis $\mathrm{B}$ virus $\mathrm{X}$ protein can also regulate $U C A 1$ expression and affect the proliferation of cancer cells, including HCC, GC and CRC cells (53-56). 


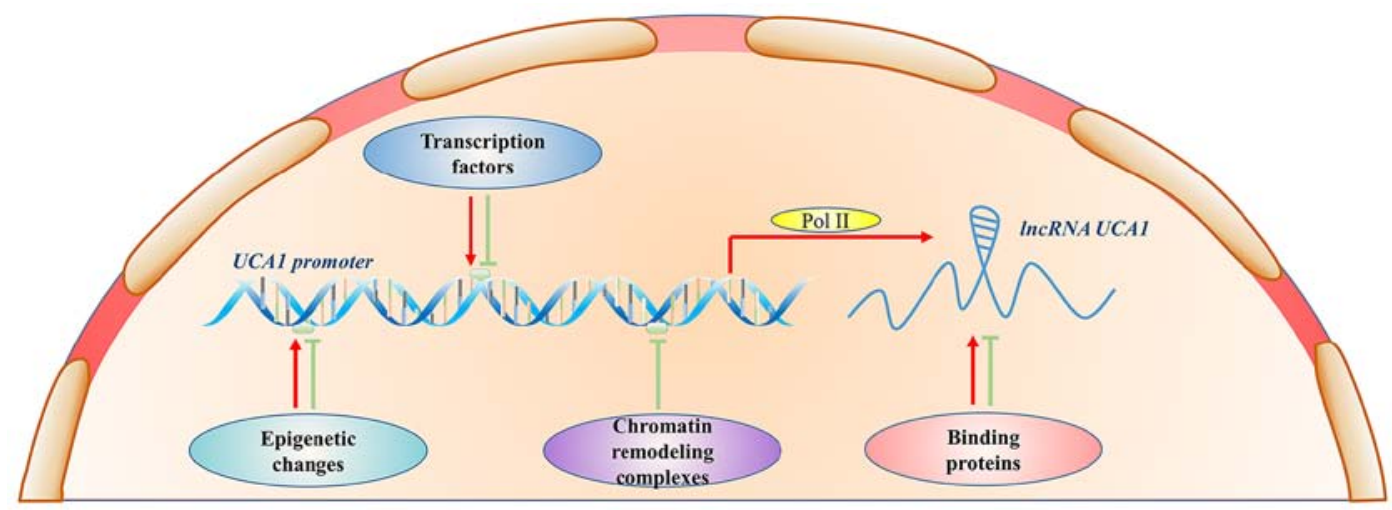

Figure 2. Regulatory mechanisms of UCA1. Transcription factors, epigenetic changes, chromatin remodeling complexes and binding proteins positively or negatively regulate $U C A 1$ expression. UCA1, urothelial carcinoma associated 1; lncRNA, long non-coding RNA; Pol II, RNA polymerase II.

\section{Signaling pathways regulated by $U C A 1$}

PI3K/AKT signaling pathway. The PI3K/AKT signaling pathway is involved in important physiological activities, including cell proliferation, invasion and metastasis, and is closely associated with cancer (16,35), DN (19), SLE (18), myocardial fibrosis (57) and PD (20). Recently, the regulatory mechanisms of lncRNAs in the PI3K/AKT pathway and their effects on diseases have attracted great interest (58-60).

It has been reported that $U C A I$ can promote malignant phenotypes of PDAC by activating the AKT signaling pathway (16). This process includes the promotion of cell proliferation, invasion, EMT, inhibition of apoptosis and enhancement of 5-FU resistance (16). In bladder cancer (35) and SLE (18), UCAl is highly expressed and promotes cell proliferation by mediating the PI3K/AKT signaling pathway. UCAl knockdown inhibits proliferation and migration of glioma cells through miR-193a-mediated downregulation of cyclin-dependent kinase 6 (CDK6), and inactivates the PI3K/AKT pathway by decreasing the expression levels of phosphorylated PI3K and AKT proteins (61). In acute myeloid leukemia (AML), UCAl can be used as an endogenous sponge to compete with miR-126, which in turn suppresses activation of the PI3K/AKT signaling pathway by inhibiting the expression of RAS-related C3 botulinus toxin substrate 1 (RAC1) (62).

Recent studies have demonstrated that enhancer of zeste homolog 2 (EZH2) can promote cell cycle progression by affecting the PI3K/AKT pathway or the expression levels of cyclins (63-65). EZH2 can also be post-translationally modified by phosphorylation of AKT (66). UCAl directly interacts with $E Z H 2$ in GC and enhances EZH2 expression, which in turn activates the AKT/GSK3 $\beta /$ cyclin D1 (CCND1) axis to increase cell proliferation (36). However, UCAl suppresses p27Kip1/CDK2 signal transduction and promotes cell proliferation and tumorigenesis by recruiting EZH2 (56). In PC (67) and $\mathrm{BC}(44), U C A 1$ promotes the proliferation of cancer cells by inhibiting $p 27$ expression. $U C A 1$ can also inhibit the level of cAMP response element-binding (CREB) protein, and regulate the cell cycle of bladder cancer cells via the PI3K-dependent pathway (68). A study has reported that UCAl impairs the binding of brahma-related gene 1 ( $B R G 1)$ to the $p 21$ promoter and the chromatin remodeling activity of $B R G l$ to accelerate the proliferation of bladder cancer cells (69). Cisplatin and gemcitabine resistance in bladder cancer cells is mediated by UCAl-CREB-miR-196a-5p paradigm (70).

UCAl can inhibit PTEN and promote p-AKT expression to induce the proliferation of osteosarcoma cells (71). Notably, p-PTEN is a phosphatase, and PTEN is a negative regulator of PI3K. Dephosphorylation of PTEN can decrease activation of AKT and block its downstream signal transduction (71). In vivo studies have demonstrated that UCAI functions via the PI3K/AKT signaling pathway $(19,48,72)$. In the Sprague-Dawley rat model of DN, inhibition of UCAl decreases renal pathological damage, improved renal function and decreased inflammation in $\mathrm{DN}$ rats by suppressing the PI3K/AKT signaling pathway (19). In addition, downregulation of $U C A 1$ expression can ameliorate the damage of dopaminergic neurons by inhibiting the PI3K/AKT signaling pathway to decrease oxidative stress and inflammation in PD (20). Thus, UCAl participates in the regulation of the PI3K/AKT signaling pathway by affecting EZH2, CDK6, RAC1 and PTEN, which promote cell proliferation, invasion, metastasis and drug resistance, and inhibit apoptosis in diseases $(36,61,62,71)$.

Several studies have demonstrated that mammalian target of rapamycin (mTOR) is the core component downstream of the PI3K/AKT pathway (73-75). IncRNAs participate in cell proliferation, apoptosis, invasion and energy metabolism by regulating the mTOR signaling pathway (73). It has been reported that upregulation of UCAI expression confers tamoxifen resistance in $\mathrm{BC}$ cells, partly by activating the mTOR signaling pathway (74). In addition, UCAl interacts with mTOR to inhibit $p 27$ and miR-143 expression; however, the expression levels of Kirsten rat sarcoma viral oncogene homolog and CCND1 significantly increase, which results in the proliferation, EMT and metastasis of CRC cells (55). Notably, it has been demonstrated that UCAI increases CREBI expression by acting as a competitive endogenous RNA (ceRNA) of miR-582, thus promoting EMT via the CREB1-mediated mTOR pathway, which results in osteosarcoma metastasis (72). In cardiomyocytes, UCAI decreases miR-122 and miR-143 expression, and regulates their downstream mTOR signaling pathway to inhibit oxygen-glucose deprivation (OGD) or hypoxia/reoxygenation (H/R)-induced apoptosis and injury (76,77). UCAl knockdown can also regulate signal 
Table I. Regulation of signaling pathways mediated by UCA1 as a competitive endogenous RNA of miRNAs.

\begin{tabular}{|c|c|c|c|c|c|}
\hline miRNA & Target gene & Signaling pathways & Biological functions & Diseases & (Refs.) \\
\hline miR-193a & CDK6 & $\begin{array}{l}\text { PI3K/AKT, ERK/MAPK } \\
\text { and Notch }\end{array}$ & $\begin{array}{l}\text { Migration, invasion and } \\
\text { apoptosis }\end{array}$ & Glioma & $(61)$ \\
\hline miR-126 & $\mathrm{RAC1}$ & PI3K/AKT and JAK/STAT & $\begin{array}{l}\text { Proliferation, migration and } \\
\text { invasion }\end{array}$ & AML & $(62)$ \\
\hline miR-582 & CREB1 & $\mathrm{PI} 3 \mathrm{~K} / \mathrm{AKT} / \mathrm{mTOR}$ & EMT & Osteosarcoma & $(72)$ \\
\hline miR-143 & HK2 & $\mathrm{PI} 3 \mathrm{~K} / \mathrm{AKT} / \mathrm{mTOR}$ & Glycolysis & Bladder cancer & (79) \\
\hline $\operatorname{miR}-200 c$ & - & $\begin{array}{l}\mathrm{PI} 3 \mathrm{~K} / \mathrm{AKT} / \mathrm{mTOR}, \mathrm{AMPK} \\
\text { and } \mathrm{Wnt} / \beta \text {-catenin }\end{array}$ & $\begin{array}{l}\text { Proliferation, migration and } \\
\text { invasion }\end{array}$ & Hemangioma & (78) \\
\hline miR-185-5p & MMP-9 & $\mathrm{Wnt} / \beta$-catenin & EMT & Melanoma & $(84)$ \\
\hline $\operatorname{miR}-122$ & - & $\begin{array}{l}\mathrm{PI} 3 \mathrm{~K} / \mathrm{AKT} / \mathrm{mTOR} \text { and } \\
\mathrm{JNK} / \mathrm{p} 38 \mathrm{MAPK}\end{array}$ & Apoptosis & AMI & (76) \\
\hline miR-122 & CLIC1 & ERK/MAPK & Metastasis & CCA & (89) \\
\hline miR-203 & $\mathrm{MEF} 2 \mathrm{C}$ & $\mathrm{NF}-\kappa \mathrm{B}$ & Inflammation & Epilepsy & (93) \\
\hline $\operatorname{miR}-331-3 p$ & IL6R & JAK2/STAT3 & Proliferation and apoptosis & $\mathrm{MM}$ & (98) \\
\hline $\operatorname{miR}-15 \mathrm{a}$ & - & Hippo and JNK/p38 MAPK & Proliferation and EMT & Thyroid cancer & $(90)$ \\
\hline $\operatorname{miR}-124$ & JAG1 & Notch & Invasion and EMT & Tongue cancer & (46) \\
\hline $\operatorname{miR}-145-5 p$ & SMAD5 & TGF- $\beta /$ SMAD & Chondrogenic differentiation & Osteoarthritis & $(103)$ \\
\hline $\operatorname{miR}-124-3 p$ & SMAD4 & TGF- $\beta /$ SMAD & Chondrogenic differentiation & Osteoarthritis & $(103)$ \\
\hline $\begin{array}{l}\text { miR-1 } \\
\text { miR-203a }\end{array}$ & Slug & TGF- $\beta /$ SMAD & EMT & $\mathrm{BC}$ and glioma & $(33,104)$ \\
\hline miR-182-5p & DLL4 & Notch & $\begin{array}{l}\text { Proliferation, migration and } \\
\text { apoptosis }\end{array}$ & Renal cancer & (11) \\
\hline $\operatorname{miR}-143$ & MDM2 & PI3K/AKT/mTOR and p53 & Apoptosis & AMI & (77) \\
\hline
\end{tabular}

transduction of mTOR via miR-200c and miR-195, and inhibit the proliferation and invasion of hemangioma cells and microvascular endothelial cells (78). Furthermore, bladder cancer cells preferentially metabolize glucose by aerobic glycolysis, known as the Warburg effect (79). UCAl promotes glycolysis and upregulates hexokinase 2 expression via the mTOR-STAT3/miR-143 pathway in bladder cancer cells (79). Taken together, these findings suggest that UCAl can directly or indirectly activate the mTOR signaling pathway by serving as a regulator of miR-582 and miR-195, and affect the expression of proteins, such as CREB1 and CCND1, to promote cell proliferation, drug resistance and inhibit apoptosis.

Wnt/ $\beta$-catenin signaling pathway. The Wnt/ $\beta$-catenin signaling pathway is a developmental signal-transduction pathway. Activation of this pathway can result in the proliferation, invasion, metastasis and differentiation of cancer cells, ultimately inducing tumorigenesis (80). The canonical Wnt pathway activates gene transcription through $\beta$-catenin accumulation in the cytoplasm and translocation to the nucleus (80).

Several studies have demonstrated that UCAI promotes cell proliferation and EMT in osteosarcoma (38), glioma (81) and papillary thyroid carcinoma (82) by activating the $\mathrm{Wnt} / \beta$-catenin signaling pathway. In addition, the $\mathrm{Wnt} / \beta$-catenin signaling pathway is closely associated with chemoresistance $(12,81,83)$. UCAl induces chemoresistance to cisplatin and temozolomide in glioma and decreases the sensitivity of BC cells to tamoxifen via the $\mathrm{Wnt} / \beta$-catenin signaling pathway $(81,83)$. Notably, UCAl can also increase cisplatin resistance of bladder cancer cells by activating Wnt signaling in a Wnt6-dependent manner (12).

Previous studies have reported that $U C A 1$ regulates the Wnt/ $\beta$-catenin signaling pathway via miR-200c and miR-185-5p, and affects the proliferation and EMT in hemangioma (78) and melanoma cells (84), respectively. In osteosarcoma, UCAl knockdown inhibits miR-301a expression and induces the silencing of C-X-C chemokine receptor type 4 (CXCR4), thus decreasing cell proliferation and metastasis (85). In addition, downregulation of miR-301a expression decreases the levels of Wnt3a, Wnt5a and $\beta$-catenin proteins, which in turn inhibits the Wnt/ $\beta$-catenin signaling pathway (85). UCAl regulates matrix metalloproteinase- 9 expression, which is a downstream gene of $\mathrm{Wnt} / \beta$-catenin (86), via miR-204 and increases trophoblast cells migration (51). Notably, enhanced $U C A 1$ expression upregulates the expression of highly upregulated in liver cancer $(H U L C)$ by inhibiting $H U L C$ promoter 
Table II. Upstream regulation of UCA1 expression.

\begin{tabular}{|c|c|c|c|c|}
\hline Type of factor & Regulation & Regulatory factor & Diseases & (Refs.) \\
\hline \multirow{7}{*}{ Transcription factors } & Promotion & $\mathrm{C} / \mathrm{EBP} \alpha$ & Bladder cancer & $(32)$ \\
\hline & Promotion & $\mathrm{C} / \mathrm{EBP} \beta$ & Bladder cancer & (34) \\
\hline & Promotion & Ets-2 & Bladder cancer & $(35)$ \\
\hline & Promotion & SP1 & GC & (36) \\
\hline & Promotion & MYB & $\mathrm{HCC}$ & (37) \\
\hline & Promotion & EP300 & Osteosarcoma & (38) \\
\hline & Promotion & $\mathrm{C} / \mathrm{EBP} \alpha$ & HNSCC & (39) \\
\hline \multirow[t]{3}{*}{ Chromatin remodeling complexes } & Inhibition & SATB 1 & $\mathrm{BC}$ & (29) \\
\hline & Inhibition & ARID1A & $\mathrm{BC}$ & $(30)$ \\
\hline & Inhibition & CAPER $\alpha /$ TBX3 repressor complex & UMS & (43) \\
\hline Epigenetic changes & Inhibition & SAM & $\mathrm{HCC}$ & $(31)$ \\
\hline \multirow[t]{2}{*}{ Binding proteins } & Promotion & HnRNPI & $\mathrm{BC}$ & (44) \\
\hline & Inhibition & IMP1 & $\mathrm{BC}$ & (45) \\
\hline \multirow[t]{10}{*}{ Others } & Promotion & TGF- $\beta$ & Tongue cancer & (46) \\
\hline & Promotion & BMP9 & $\mathrm{BC}$ & (33) \\
\hline & Promotion & TAZ/YAP and TEAD complexes & $\mathrm{BC}$ & (47) \\
\hline & Inhibition & Metformin & $\mathrm{EH}$ & (50) \\
\hline & Inhibition & Metformin & $\mathrm{PE}$ & (51) \\
\hline & Inhibition & lncRNA GAS8-AS1 & Osteosarcoma & $(52)$ \\
\hline & Inhibition & UPF1 & $\mathrm{HCC}$ & (53) \\
\hline & Promotion & PA & $\mathrm{GC}$ & (54) \\
\hline & Promotion & CAFs & $\mathrm{CRC}$ & (55) \\
\hline & Promotion & HBx & $\mathrm{HCC}$ & (56) \\
\hline
\end{tabular}

UCA1, urothelial carcinoma associated 1; ARID1A, AT-rich interaction domain 1A; BC, breast cancer; BMP9, bone morphogenetic protein 9; C/EBP, CCAAT/enhancer binding protein; CAFs, cancer-associated fibroblasts; CRC, colorectal cancer; EH, endometrial hyperplasia; EP300, E1A binding protein p300; ETS-2, E26 transformation-specific transcription factor 2; GC, gastric cancer; HBx, hepatitis B virus X protein; HCC, hepatocellular carcinoma; HNSCC, head and neck squamous cancer; IMP1, insulin-like growth factor 2 mRNA-binding protein 1; PA, palmitic acid; PE, pre-eclampsia; SAM, S-adenosylmethionine; SATB1, special AT-rich sequence binding protein 1; SP1, specificity protein 1; TAZ, transcriptional co-activator with PDZ binding motif; TEAD, transcriptional enhancer TEA domain; TGF- $\beta$, transforming growth factor- $\beta$; UMS, ulnar-mammary syndrome; UPF1, up-frameshift protein 1; YAP, yes-associated protein.

methylation, and upregulates $\beta$-catenin by promoting $\beta$-catenin promoter-enhancer chromatin DNA looping formation, which in turn promotes the malignant transformation of hepatocyte-like cells (87). Collectively, these findings suggest that $U C A 1$ is involved in tumorigenesis via the $\mathrm{Wnt} / \beta$-catenin signaling pathway by regulating miRNAs, such as miR-204 and miR-301a, and lncRNAs, such as HULC.

MAPK signaling pathway. The MAPK pathway participates in the regulation of cell proliferation, invasion, metastasis, apoptosis and differentiation, and is closely associated with the occurrence of various diseases such as PDAC (16), melanocytes (13) and acute myocardial infarction (76). Its functional pattern predominantly involves phosphorylating nuclear transcription factors, cytoskeletal proteins and enzymes (88). The MAPK signaling pathway includes four pathways: The ERK, P38, SAPK/JNK and ERK5/BMK1 pathways. As an important regulatory gene, $U C A 1$ can participate in the regulation of the MAPK signaling pathway (88).

A previous study demonstrated that $U C A 1$ promotes the proliferation, migration and invasion of PDAC cells, and decreases apoptosis and increases 5-FU resistance by activating the ERK signaling pathway (16). In addition, UCAl negatively regulates the CREB/MITF/melanogenesis axis by suppressing the ERK and JNK signaling pathways in melanocytes, thus inhibiting the expression of melanogenesis-related genes in melanocytes (13).

UCAl knockdown activates the AMPK signaling pathway by upregulating a series of miRNAs $(61,76,78,89)$. In addition, UCA1 knockdown regulates AMPK signal transduction via miR-200c and suppresses the proliferation, migration and invasion of hemangioma cells (78). Furthermore, in acute myocardial infarction, UCAI decreases OGD aroused cell apoptosis and injury by downregulating miR-122 expression and suppressing its downstream JNK/p38 MAPK signaling pathway (76). Knockdown of UCAl inactivates the MAPK signaling pathway by downregulating $C D K 6$ expression mediated by miR-193a, which decreases the proliferation and promotes the apoptosis of glioma cells (61). In cholangiocarcinoma, UCA1 upregulates chloride intracellular channel 1 (CLIC1) expression by inhibiting miR-122 expression and activating the ERK/MAPK signaling pathway to promote the metastasis of malignant cells (89). In addition, 
UCA1 promotes the viability and EMT of TPC-1 cells by competing with miR-15a and activating the Hippo and JNK signaling pathways in human thyroid cancer (90). Taken together, these findings suggest that UCA1 activates the MAPK signaling pathways by regulating CLIC1 and CDK6 expression, inducing cell proliferation, migration and drug resistance, and inhibiting apoptosis.

Nuclear factor-kappa $B(N F-\kappa B)$ signaling pathway. NF- $\mathrm{B}$ is an extensively expressed multi effect transcription factor. It is a heterotrimer composed of p50, p65 and IкB (91). The $\mathrm{NF}-\kappa \mathrm{B}$ signaling pathway is activated by several factors, including extracellular stimulation and transcription factors (91). Activated NF- $\kappa \mathrm{B}$ signaling pathway mediates several biological processes, such as cell proliferation, tumor metastasis and inflammation (91).

$U C A 1$ can activate the NF- $\kappa \mathrm{B}$ signaling pathway through inflammatory cytokines like IL6 (92) and transcription factors like MEF2C (93). Several studies have demonstrated that the $\mathrm{NF}-\kappa \mathrm{B}$ signaling pathway can be regulated by $U C A 1(85,94)$. In osteosarcoma, inhibition of UCAl downregulates miR-301a expression and decreases $C X C R 4$ expression, thus suppressing cell proliferation and metastasis (85). Furthermore, miR-301a positively regulates the phosphorylation of $\mathrm{I} \kappa \mathrm{B}$ and $\mathrm{p} 65$ proteins and activates the $\mathrm{NF}-\kappa \mathrm{B}$ signaling pathway (85). UCA 1 knockdown exerts an anticancer effect on GC cells by rescuing miR-182 expression to activate the $\mathrm{NF}-\kappa \mathrm{B}$ and $\mathrm{PI} 3 \mathrm{~K} / \mathrm{AKT} / \mathrm{GSK} 3 \beta$ signaling pathways (94). In HCC, the synergism between $U C A 1$ and inflammatory cytokine IL6 promotes SUV39H1 expression. Notably, methyltransferase-like 3, which binds to $S U V 39 H 1$ mRNA, is also upregulated. Excessive $S U V 39 H 1$ expression can increase the expression of tri-methylation of histone 3 lysine 9 trimethylation (H3K9me3) (92). Notably, under inflammatory conditions, H3K9me3 induces phosphorylation of $\mathrm{NF}-\kappa \mathrm{B}$, resulting in the malignant transformation of hepatocyte-like stem cells (92). This synergism between UCA 1 and IL6 can aggravate the malignant transformation of hepatocyte-like stem cells via the $\mathrm{NF}-\kappa \mathrm{B}$ signaling pathway (92). In addition, $U C A 1$ regulates the inflammatory responses in epilepsy by regulating the miR-203-mediated myocyte enhancer factor $2 \mathrm{C} / \mathrm{NF}-\kappa \mathrm{B}$ signaling pathway (93).

JAK/STAT signaling pathway. The JAK/STAT signaling pathway is a common pathway for various cytokines and growth factors to transmit signals within cells (95). It mediates several biological responses, including cell proliferation, differentiation, migration, apoptosis and immune regulation (95). Previous studies have demonstrated that lncRNAs play a regulatory role in the JAK/STAT signaling pathway $(96,97)$.

$U C A 1$ promotes the development of cancer cells by activating the JAK/STAT signaling pathway, including multiple myeloma (MM) (98), AML (62) and pre-eclampsia (99). UCAI activates the JAK2/STAT3 pathway via the miR-331-3p/IL6R axis in MM, and regulates cell proliferation and apoptosis (98). In AML, UCA1 competes with miR-126 as an endogenous sponge. miR-126 suppresses activation of the JAK/STAT signaling pathway by decreasing RAC1 expression, thus inhibiting cell proliferation, migration and invasion (62). Notably, UCAl exerts opposite effects on the regulation of the JAK/STAT signaling pathway in some non-cancerous cells $(99,100)$. A study has reported that $U C A 1$ expression is upregulated in trophoblast cells of pre-eclampsia pregnancy, and it can inhibit the invasion and proliferation of trophoblast cells by downregulating JAK2 expression (99). In addition, overexpression of UCAl inhibits activation of the JAK/STAT signaling pathway, which in turn inhibits activation of astrocytes in temporal lobe epilepsy (100). It is suggested that $U C A 1$ promotes IL6R and RAC1 expression to stimulate the JAK/STAT signaling pathway, which increases cell proliferation and invasion in several tumors, while $U C A l$ exerts opposing effects in some non-cancerous cells $(62,98)$.

TGF- $\beta /$ SMAD signaling pathway. The TGF- $\beta$ superfamily is composed of secretory polypeptide molecule TGF- $\beta$, activins, inhibins and BMPs, and participates in various biological activities, such as cell invasion and migration (101). The TGF- $\beta$ superfamily is involved in cartilage and bone formation, inflammation, regulation of endocrine functions, and formation and development of tumors (101). SMADs are important molecules for intracellular TGF- $\beta$ signal transduction (101).

Previous studies have demonstrated that EMT induced by TGF- $\beta 1$ is an important reason for the invasion and migration of cancer cells $(46,102)$. The $U C A 1 / \mathrm{miR}-124$ axis regulates TGF- $\beta 1$-induced EMT and invasion of tongue cancer cells (46). In addition, UCA1 promotes the proliferation of MM cells by targeting TGF- $\beta$ (102). SMAD4 and SMAD5, two members of SMADs, are important elements involved in the TGF- $\beta$ pathway (103). It has been confirmed that UCAl regulates the TGF- $\beta$ signaling pathway via the miR-145-5p/SMAD5 and miR-124-3p/SMAD4 axes and promotes chondrogenic differentiation of human bone marrow mesenchymal stem cells (103). Notably, UCAl competitively binds with miR-1 and miR-203a to upregulate the expression of Slug, a downstream effector of TGF- $\beta$ (104), and subsequently regulates EMT in glioma cells (104) and BC cells (33).

Other signaling pathways. UCAI also participates in the regulation of othersignaling pathways, including the Notch,Hippo and p53 signaling pathways. In human glioma, UCA1 knockdown inhibits the proliferation and migration of cells through miR-193a-mediated downregulation of CDK6, and blocks the Notch signaling pathway by decreasing the expression levels of phosphorylated Notch1, Notch2 and Notch3 proteins (61). In renal cell carcinoma, UCA1 upregulates Delta-like 4 (DLL4) expression by acting as a ceRNA of miR-182-5p, and induces the EMT process via the DLL4-mediated Notch pathway, which in turn promotes cell proliferation and migration, and inhibits apoptosis (11). Furthermore, UCAl can form a ribonucleoprotein complex with Mps one binder kinase activator-1, large tumor suppressor 1 and YAP, which decreases the phosphorylation of YAP (105). Dephosphorylated YAP translocates into the nucleus and combines with TEAD protein, inhibiting the key proteins of the Hippo signaling pathway and promoting proliferation, migration and invasion of PC cells (105). Conversely, $U C A 1$ activates the Hippo signaling pathway by downregulating miR-15a expression and increasing cell viability and EMT in human thyroid cancer (90). In cardiomyocytes, UCAl inhibits H/R-induced apoptosis by decreasing miR-143 expression and suppressing its downstream p53 signaling pathway (77). 
Furthermore, UCA1 can regulate the p53 signaling pathway via miR-143 and MDM2; the Notch signaling pathway via CDK6 and DLL4 or regulate YAP and other signaling pathways, which promotes cell proliferation, EMT, migration and invasion, and inhibits cell apoptosis $(11,61,105)$.

\section{Clinical applications of $U C A 1$}

Several studies have reported that UCAI has potential clinical applications (106-109). Currently, there are three common clinical applications of UCA1: Acts as a diagnostic biomarker $(110,111)$, prognostic biomarker $(112,113)$ and therapeutic target (87). The use of UCAI as a therapeutic target for reversing drug resistance has been extensively investigated $(22,83)$.

UCAl as a diagnostic biomarker. Early diagnosis is beneficial to the prognosis of diseases. Poor prognosis is mainly attributed to the metastasis of cancer cells, drug resistance and tumor recurrence, which are closely associated with late diagnosis (114). Thus, it is important to improve the early diagnostic rate of patients. Recently, several studies have demonstrated that lncRNAs have great potential to be used as biomarkers for disease diagnosis, including UCAI (115-117).

$U C A 1$ is highly specific and easy to be detected in serum, plasma and urine. Liquid biopsy is becoming a novel method for disease detection $(72,118)$. In laryngeal squamous cell carcinoma (110), NSCLC (111), osteosarcoma (72) and HCC (118), serum UCAl levels of patients are higher than that of the healthy control population. Notably, UCAl secreted by exosomes into the serum of patients can promote the development of prostate cancer (PCa) (114). In addition, serum UCAI expression is significantly higher in patients with $\mathrm{HCC}$ than those with benign liver disease, which helps to distinguish the two groups (119). In non-cancerous diseases, UCAl can limit the inflammatory responses in epilepsy (93), and UCA1 expression is higher in patients with non-refractory epilepsy than those with refractory epilepsy (120). Notably, combined measurement of UCA 1 levels in serum and plasma can increase the sensitivity and specificity for the diagnosis of some malignancies (119). In addition, UCAl expression is higher in the urine of patients with PCa compared with healthy controls (114). Taken together, these findings suggest that UCAI has the potential to be used as a biomarker for diagnosis and screening of diseases.

Increasing evidence suggest that the combination of UCAI and other lncRNAs may exhibit better diagnostic performance. As a predictor of CRC, the combination of UCA1, HOXA transcript at the distal tip and plasmacytoma variant translocation 1 has better diagnostic performance compared with $U C A 1$ alone, and can be used to screen patients with advanced CRC (115). Another study demonstrated that the combination of $U C A 1$, gastric cancer high expressed transcript 1, taurine upregulated gene 1 and $p 21$-associated ncRNA DNA damage activated can improve the diagnostic ability and significance of GC (116). Furthermore, when comparing patients with bladder cancer with healthy controls, the combination of UCA1, circFARSA and circSHKBPI has better diagnostic performance compared with UCAI alone (117).

Early differential diagnosis of cancer and precancerous lesions is an important method to decrease the risk of recurrence

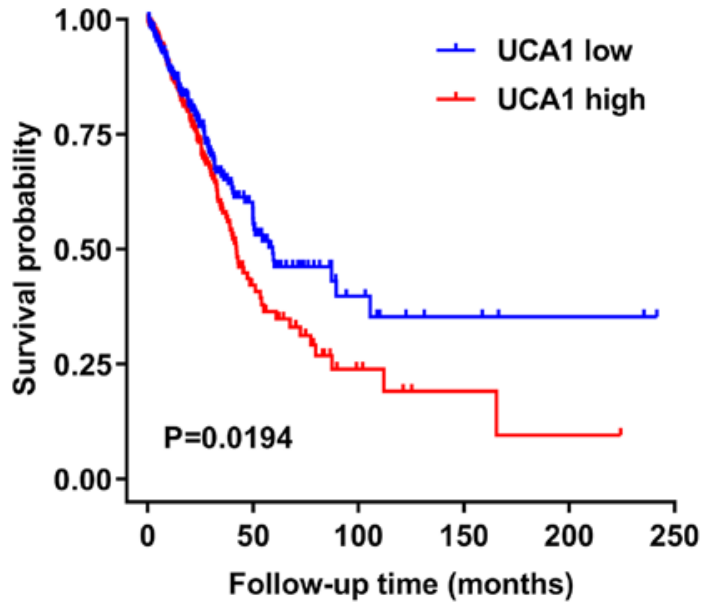

Figure 3. Association between $U C A 1$ expression and survival time of patients with non-small cell lung cancer, based on The Cancer Genome Atlas data. UCA1, urothelial carcinoma associated 1.

and improve prognosis (121). A study has demonstrated that the combination of $U C A 1, \mathrm{HOX}$ transcript antisense intergenic RNA, hydatidiform mole associated and imprinted and metastasis-associated lung adenocarcinoma transcript 1 can distinguish between patients with bladder cancer and patients with urocystitis, with a sensitivity and specificity of $95.7 \%$ and $94.3 \%$, respectively (121). Collectively, these findings suggest that it is feasible to use $U C A 1$ as a diagnostic biomarker. However, further studies are required to verify the clinical applications of $U C A 1$.

UCA1 as a prognostic biomarker. With the rapid growth of disease morbidity and mortality, overall prognosis will become the principal determinant of global public health (122). Surgery is one of the routine therapies for cancer; however, its complications and recurrence affect the prognosis of patients (122). Recent studies have demonstrated that UCA1 is closely associated with clinicopathological characteristics, including vascular invasion, lymph node metastasis and TNM stage, and can be used as a prognostic biomarker of diseases $(24,25,123)$. However, there is no doubt whether further investigation on the role of $U C A I$ as a prognostic marker will contribute to the treatment of cancer.

UCAl is closely associated with tumor size, histological differentiation, stage of lymph node metastasis, depth of invasion, vascular invasion, OS, RFS and prognostic biomarkers (Table III). It has been reported that in some cancers, such as CRC (24), HCC (23), GC (8), adrenal cortical carcinoma (124) and esophageal cancer (125), survival probability of patients is associated with $U C A 1$ expression. The Cancer Genome Atlas (https://cancergenome.nih.gov) data for lung adenocarcinoma revealed that the survival probability of patients with NSCLC, with high $U C A 1$ expression, is unfavorable than those with low $U C A 1$ expression (Fig. 3). Previous studies have suggested that overexpression of $U C A 1$ in $\mathrm{CRC}$ indicates a large tumor, advanced TNM stage, deeply infiltrated lymph node, positive lymph node metastasis and poor OS $(22,24)$. Other studies have reported that $U C A 1$ expression in GC tissues and cells is positively associated with TNM stage, lymph node infiltration, lymph node metastasis and OS $(8,9)$. Notably, UCA 1 expression 
Table III. Role of UCA1 in clinical correlation and prognosis of diseases.

\begin{tabular}{|c|c|c|c|}
\hline Disease & $\begin{array}{l}\text { Upregulation/ } \\
\text { downregulation }\end{array}$ & Clinical correlation & (Refs.) \\
\hline Renal cancer & Upregulation & Degree of differentiation, TNM stage and lymph node metastasis & $(11,107)$ \\
\hline SLE & Upregulation & SLEDAI & $(18)$ \\
\hline $\mathrm{CRC}$ & Upregulation & $\begin{array}{l}\text { Tumor size, tumor stage, lymph node infiltration, lymph node } \\
\text { metastasis and OS }\end{array}$ & $(22,24)$ \\
\hline $\mathrm{HCC}$ & Upregulation & Tumor stage, TNM stage, Microvascular infiltration and OS & $(23)$ \\
\hline GC & Upregulation & $\begin{array}{l}\text { TNM stage, tumor stage, lymph node infiltration, lymph node } \\
\text { metastasis and OS }\end{array}$ & $(8,9)$ \\
\hline Tongue cancer & Upregulation & TNM staging, lymph node metastasis, lymph node infiltration and OS & $(46)$ \\
\hline Osteosarcoma & Upregulation & Tumor stage, tumor size and OS & $(72)$ \\
\hline OSCC & Upregulation & TNM stage, lymph node metastasis and OS & $(108)$ \\
\hline PTC & Upregulation & Tumor size, tumor stage, lymph node metastasis and OS & $(26,82)$ \\
\hline MM & Upregulation & OS & $(98,102)$ \\
\hline $\mathrm{PC}$ & Upregulation & Tumor stage and OS & $(27,105)$ \\
\hline LSCC & Upregulation & Lymph node metastasis and OS & $(110)$ \\
\hline NSCLC & Upregulation & TNM stage, tumor size and OS & $(111)$ \\
\hline $\mathrm{PCa}$ & Upregulation & Edmondson-Steiner grade, TNM stage and lymph node metastasis & $(112,114)$ \\
\hline Epilepsy & Upregulation & Classification of epilepsy & $(120)$ \\
\hline Glioma & Upregulation & TNM stage, tumor size, lymph node metastasis and OS & $(109)$ \\
\hline Cholangiocarcinoma & Upregulation & $\begin{array}{l}\text { TNM stage, tumor stage, lymph node infiltration, lymph node } \\
\text { metastasis, RFS and OS }\end{array}$ & $(10)$ \\
\hline $\mathrm{OC}$ & Upregulation & TNM stage, lymph node metastasis and OS & $(128)$ \\
\hline NPC & Upregulation & Tumor stage, lymph node metastasis and OS & $(113)$ \\
\hline $\mathrm{ACC}$ & Upregulation & TNM stage and lymph node metastasis & $(124)$ \\
\hline LUAD & Upregulation & TNM stage, lymph node metastasis, RFS and OS & $(28)$ \\
\hline Melanoma & Upregulation & Tumor stage and lymph node metastasis & $(106)$ \\
\hline $\mathrm{EC}$ & Upregulation & Degree of differentiation, TNM stage, lymph node metastasis and OS & $(125)$ \\
\hline
\end{tabular}

UCA1, urothelial carcinoma associated 1; ACC, adrenal cortical carcinoma; CRC, colorectal cancer; EC, esophageal cancer; GC, gastric cancer; HCC, hepatocellular carcinoma; LSCC, laryngeal squamous cell carcinoma; LUAD, lung adenocarcinoma; MM, multiple myeloma; NPC, nasopharyngeal carcinoma; NSCLC, non-small cell lung cancer; OC, ovarian cancer; OS, overall survival; OSCC, oral squamous cell carcinoma; PC, pancreatic cancer; PCa, prostate cancer; PTC, papillary thyroid carcinoma; RFS, relapse-free survival; SLEDAI, systemic lupus erythematosus disease activity index; TNM, tumor-node-metastasis.

in the plasma of patients with GC significantly decreases following surgery (126). Thus, UCAl can be used as an index of postoperative prognosis. In addition, $U C A l$ expression is significantly upregulated in SLE, which is positively associated with SLE disease activity index (18). Collectively, these findings suggest that UCAl can be used as an independent prognostic factor to monitor the occurrence and development of diseases.

UCA1 as a therapeutic target. With a better understanding of the pathogenesis of diseases, several molecules and signal transduction pathways are likely to be suitable for targeted therapy (122). Given that UCAI exerts carcinogenic effects associated with several molecules and cascade reactions, it has been confirmed as an ideal therapeutic target $(22,70,81)$. Targeted knockout of $U C A 1$ can be used to improve radiosensitivity, inhibit cancer metastasis, prevent cancer growth in vivo, promote apoptosis and reverse drug resistance of cancer cells $(21,37,72)$. Clinical applications of $U C A 1$ as a therapeutic target for reversing drug resistance has attracted great interest $(21,127)$. UCAl is also known as a cancer upregulated drug resistant gene (87). Previous studies have reported that downregulating $U C A l$ expression can reverse drug resistance in cancers, and some drugs for chemotherapy exert an anticancer role by mediating UCA1 (Table IV), including cisplatin $(70,81)$, tamoxifen (83), paclitaxel (128), 5-FU (22), Adriamycin (129), temozolomide (81), cetuximab (130), trastuzumab (131), imatinib (132), docetaxel (133) and gemcitabine (70). These drugs provide the possibility of chemotherapy-related clinical applications, and studies have demonstrated that UCAI knockdown can reverse multidrug resistance in retinoblastoma (127) and bladder cancer (21). In addition, the combination of UCAl-targeted therapy and programmed cell death 1 (PD-1) immune checkpoint blockade has a better synergistic effect following CRISPR-Cas9-mediated UCA1 knockdown (134). However, further studies are required to confirm the therapeutic value of $U C A 1$ for diseases. 
Table IV. Role of UCA1 in tumor drug resistance.

\begin{tabular}{|c|c|c|c|}
\hline Cancer type & Drug resistance & Mechanisms & (Refs.) \\
\hline PDAC & $5-\mathrm{FU}$ & $\begin{array}{l}\text { UCA1 promotes EMT by activating the AKT and ERK } \\
\text { signaling pathways in PDAC cells }\end{array}$ & $(16)$ \\
\hline Bladder cancer & Cisplatin/gemcitabine & $\begin{array}{l}\text { UCA1 inhibits cisplatin/gemcitabine-induced apoptosis } \\
\text { via targeting p27Kip1 }\end{array}$ & $(70)$ \\
\hline Bladder cancer & Cisplatin & UCA1 upregulates Wnt6 expression & $(12)$ \\
\hline Bladder cancer & Multidrug resistance & UCA1 inhibits autophagy by upregulating ATG7 expression & $(21)$ \\
\hline $\mathrm{OC}$ & Paclitaxel & UCA1 upregulates ABCB1 expression & $(128)$ \\
\hline $\mathrm{CRC}$ & $5-\mathrm{FU}$ & UCA1 upregulates CREB1 expression & $(22)$ \\
\hline AML & Adriamycin & UCA1 upregulates the HK2 expression & $(129)$ \\
\hline $\mathrm{BC}$ & Tamoxifen & UCA1 activates the mTOR signaling pathway & (74) \\
\hline $\mathrm{BC}$ & Tamoxifen & UCA1 activates the $\mathrm{Wnt} / \beta$-catenin signaling pathway & $(83)$ \\
\hline $\mathrm{BC}$ & Trastuzumab & UCA1 upregulates YAP1 expression & $(131)$ \\
\hline Glioma & Cisplatin/temozolomide & UCA1 activates the $\mathrm{Wnt} / \beta$-catenin signaling pathway & $(81)$ \\
\hline $\mathrm{CRC}$ & Cetuximab & UCA1 in exosomes transmits cetuximab resistance & $(130)$ \\
\hline CML & Imatinib & UCA1 upregulates MDR1 expression & $(132)$ \\
\hline $\mathrm{PCa}$ & Docetaxel & UCA1 upregulates Sirt1 expression & $(133)$ \\
\hline Retinoblastoma & Multidrug resistance & UCA1 upregulates STMN1 expression & $(127)$ \\
\hline
\end{tabular}

\section{Conclusions and perspective}

UCA1 can regulate a series of signaling pathways by acting as a ceRNA of several miRNAs, and affect epigenetic, transcriptional and post-transcriptional regulation. It plays a regulatory role in several biological functions, including cell proliferation, apoptosis, migration, invasion and drug resistance. In addition, $U C A 1$ can be used as a potential biomarker for disease diagnosis and treatment. For some diseases, the combination of UCAl and other lncRNAs has demonstrated better diagnostic and screening performance. Strategies, such as CRISPR-Cas9 system or siRNA-mediated knockout, and the combination of UCA1-targeted therapy and PD-1 immune checkpoint blockade may be used to transform $U C A 1$ from basic research into clinical practice.

Recently, although great progress has been made in understanding the biology of $U C A 1$, even in its therapeutic applications, several unknown areas in $U C A 1$ research remain. First, the lack of effective methods to investigate RNA secondary and tertiary structures and nuclear ultrastructure of UCAI impedes the study on the composition of its isoforms and tissue-specific regulation (4). Secondly, several studies have confirmed that lncRNAs can promote the drug resistance of cancer cells by regulating their stemness feature $(27,135,136,104)$; however, the mechanism by which $U C A 1$ affects the drug resistance of cancer stem cells remains unclear. Some lncRNAs may play important regulatory roles in cellular biological processes via multiple pathways $(5,6)$. However, whether binding miRNAs affects the expression or function of UCA1 remains unclear. In conclusion, UCA1, as a well-known lncRNA with great clinical potential, requires increasing comprehension and in-depth study.

\section{Acknowledgements}

Not applicable.

\section{Funding}

The present review was funded by the National Natural Science Foundation of China (grant nos. 81870105 and 81770107), the Scientific Research Fund Project of Hunan Provincial Health Commission (grant no. 20201921), the National Key Research and Development Program of China (grant no. 2018YFA0107800) and the Scientific Research and Innovation Project of postgraduates in Hunan Province (grant no. CX20200970).

\section{Availability of data and materials}

Not applicable.

\section{Authors' contributions}

ZL and YW contributed to drafting the review and figures. SY, FW, and JL revised the manuscript for important intellectual content. JZ and LZ conceived the project and revised the manuscript for important intellectual content. ZL and YW confirm the authenticity of all the raw data. All authors have read and approved the final manuscript. 


\section{Ethics approval and consent to participate}

Not applicable.

\section{Patient consent for publication}

Not applicable.

\section{Competing interests}

The authors declare that they have no competing interests.

\section{References}

1. Kopp F and Mendell JT: Functional classification and experimental dissection of long noncoding RNAs. Cell 172: 393-407, 2018.

2. Cao H, Wahlestedt C and Kapranov P: Strategies to annotate and characterize long noncoding RNAs: Advantages and pitfalls. Trends Genet 34: 704-721, 2018.

3. Kaikkonen MU and Adelman K: Emerging roles of non-coding RNA transcription. Trends Biochem Sci 43: 654-667, 2018.

4. Qian X, Zhao J, Yeung PY, Zhang QC and Kwok CK: Revealing lncRNA structures and interactions by sequencing-based approaches. Trends Biochem Sci 44: 33-52, 2019.

5. Xiao G, Yao J, Kong D, Ye C, Chen R, Li L, Zeng T, Wang L, Zhang W, Shi X, et al: The Long Noncoding RNA TTTY15, Which is located on the $\mathrm{Y}$ chromosome, promotes prostate cancer progression by sponging let-7. Eur Urol 76: 315-326, 2019.

6. Kim J, Piao HL, Kim BJ, Yao F, Han Z, Wang Y, Xiao Z, Siverly AN, Lawhon SE, Ton BN, et al: Long noncoding RNA MALAT1 suppresses breast cancer metastasis. Nat Genet 50: $1705-1715,2018$

7. Wang XS, Zhang Z, Wang HC, Cai JL, Xu OW, Li MQ, Chen YC, Qian XP, Lu TJ, Yu LZ, et al: Rapid identification of UCA1 as a very sensitive and specific unique marker for human bladder carcinoma. Clin Cancer Res 12: 4851-4858, 2006.

8. Cao Y, Xiong JB, Zhang GY, Liu Y, Jie ZG and Li ZR: Long noncoding RNA UCA1 regulates PRL-3 expression by sponging MicroRNA-495 to promote the progression of gastric cancer. Mol Ther Nucleic Acids 19: 853-864, 2020.

9. Wang CJ, Zhu CC, Xu J, Wang M, Zhao WY, Liu Q, Zhao G and Zhang ZZ: The lncRNA UCA1 promotes proliferation, migration, immune escape and inhibits apoptosis in gastric cancer by sponging anti-tumor miRNAs. Mol Cancer 18: 115, 2019.

10. Li O, Yi W, Yang P, Guo C and Peng C: Long non-coding RNA UCA1 promotes proliferation and invasion of intrahepatic cholangiocarcinoma cells through targeting microRNA-122. Exp Ther Med 18: 25-32, 2019.

11. Wang W, Hu W, Wang Y, An Y, Song L, Shang P and Yue Z: Long non-coding RNA UCA1 promotes malignant phenotypes of renal cancer cells by modulating the miR-182-5p/DLL4 axis as a ceRNA. Mol Cancer 19: 18, 2020.

12. Fan Y, Shen B, Tan M, Mu X, Qin Y, Zhang F and Liu Y: Long non-coding RNA UCA1 increases chemoresistance of bladder cancer cells by regulating Wnt signaling. Febs J 281: 1750-1758, 2014

13. Pei S, Chen J, Lu J, Hu S, Jiang L, Lei L, Ouyang Y, Fu C, Ding Y, $\mathrm{Li}$ S, et al: The long noncoding RNA UCA1 negatively regulates melanogenesis in melanocytes. J Invest Dermatol 140: 152-163. $\mathrm{e} 5,2020$.

14. Neve B, Jonckheere N, Vincent A and Van Seuningen I: Epigenetic Regulation by lncRNAs: An Overview Focused on UCA1 in Colorectal Cancer. Cancers (Basel) 10: 440, 2018.

15. Liao K, Xu J, Yang W, You X, Zhong Q and Wang X: The research progress of LncRNA involved in the regulation of inflammatory diseases. Mol Immunol 101: 182-188, 2018.

16. Liang X, Qi M, Wu R, Liu A, Chen D, Tang L, Chen J, Hu X, Li W, Zhan L, et al: Long non-coding RNA CUDR promotes malignant phenotypes in pancreatic ductal adenocarcinoma via activating AKT and ERK signaling pathways. Int J Oncol 53 2671-2682, 2018

17. Yu Y, Li M, Song Y, Xu J and Qi F: Overexpression of long noncoding RNA CUDR promotes hepatic differentiation of human umbilical cord mesenchymal stem cells. Mol Med Rep 21: $1051-1058,2020$
18. Jiang CR and Li TH: Circulating UCA1 is highly expressed in patients with systemic lupus erythematosus and promotes the progression through the AKT pathway. Eur Rev Med Pharmacol Sci 22: 2364-2371, 2018

19. Shi CH, Huang Y, Li WQ and Chen RG: Influence of LncRNA UCA1 on glucose metabolism in rats with diabetic nephropathy through PI3K-Akt signaling pathway. Eur Rev Med Pharmacol Sci 23: 10058-10064, 2019.

20. Cai L, Tu L, Li T, Yang X, Ren Y, Gu R, Zhang Q, Yao H, Qu X, Wang Q and Tian J: Downregulation of lncRNA UCA1 ameliorates the damage of dopaminergic neurons, reduces oxidative stress and inflammation in Parkinson's disease through the inhibition of the PI3K/Akt signaling pathway. Int Immunopharmacol 75: 105734, 2019.

21. Wu J, Li W, Ning J, Yu W, Rao T and Cheng F: Long noncoding RNA UCA1 targets miR-582-5p and contributes to the progression and drug resistance of bladder cancer cells through ATG7-mediated autophagy inhibition. Onco Targets Ther 12: 495-508, 2019.

22. Bian Z, Jin L, Zhang J, Yin Y, Quan C, Hu Y, Feng Y, Liu H, Fei B, Mao Y, et al: LncRNA-UCA1 enhances cell proliferation and 5-fluorouracil resistance in colorectal cancer by inhibiting miR-204-5p. Sci Rep 6: 23892, 2016.

23. Zhao B, Lu Y, Cao X, Zhu W, Kong L, Ji H, Zhang F, Lin X, Guan Q, Ou K, et al: MiRNA-124 inhibits the proliferation, migration and invasion of cancer cell in hepatocellular carcinoma by downregulating IncRNA-UCA1. Onco Targets Ther 12: 4509-4516, 2019.

24. Luan Y, Li X, Luan Y, Zhao R, Li Y, Liu L, Hao Y, Oleg Vladimir B and Jia L: Circulating lncRNA UCA1 promotes malignancy of colorectal cancer via the miR-143/MYO6 Axis. Mol Ther Nucleic Acids 19: 790-803, 2020.

25. Li $\mathrm{F}$ and $\mathrm{Hu} \mathrm{CP}$ : Long Non-Coding RNA urothelial carcinoma associated 1 (UCA1): Insight into its role in human diseases. Crit Rev Eukaryot Gene Expr 25: 191-197, 2015.

26. Li N, Cui M, Yu P and Li Q: Correlations of lncRNAs with cervical lymph node metastasis and prognosis of papillary thyroid carcinoma. Onco Targets Ther 12: 1269-1278, 2019.

27. Liu Y, Feng W, Gu S, Wang H, Zhang Y, Chen W, Xu W, Lin C, Gong $\mathrm{A}$ and $\mathrm{Xu} \mathrm{M}$ : The UCA1/KRAS axis promotes human pancreatic ductal adenocarcinoma stem cell properties and tumor growth. Am J Cancer Res 9: 496-510, 2019.

28. Chen L, Cao P, Wu Q, Guo Y, Yang Y and Chen F: Overexpression of LncRNA-UCA1 correlates with lung adenocarcinoma progression and poor Prognosis. Clin Lab 65, 2019.

29. Lee JJ, Kim M and Kim HP: Epigenetic regulation of long noncoding RNA UCA1 by SATB1 in breast cancer. BMB Rep 49: 578-583, 2016

30. Guo X, Zhang Y, Mayakonda A, Madan V, Ding LW, Lin LH, Zia S, Gery S, Tyner JW, Zhou W, et al: ARID1A and CEBPa cooperatively inhibit UCA1 transcription in breast cancer. Oncogene 37: 5939-5951, 2018.

31. Sadek KM, Lebda MA, Nasr NE, Nasr SM and El-Sayed Y: Role of IncRNAs as prognostic markers of hepatic cancer and potential therapeutic targeting by S-adenosylmethionine via inhibiting PI3K/Akt signaling pathways. Environ Sci Pollut Res Int 25: 20057-20070, 2018.

32. Xue M, Li X, Wu W, Zhang S, Wu S, Li Z and Chen W: Upregulation of long non-coding RNA urothelial carcinoma associated 1 by CCAAT/enhancer binding protein alpha contributes to bladder cancer cell growth and reduced apoptosis. Oncol Rep 31: 1993-2000, 2014.

33. Li GY, Wang W, Sun JY, Xin B, Zhang X, Wang T, Zhang QF, Yao LB, Han H, Fan DM, et al: Long non-coding RNAs AC026904.1 and UCA1: A 'one-two punch' for TGF- $\beta$-induced SNAI2 activation and epithelial-mesenchymal transition in breast cancer. Theranostics 8: 2846-2861, 2018.

34. Jin B, Gong Y, Li H, Jiao L, Xin D, Gong Y, He Z, Zhou L, Jin Y, Wang $\mathrm{X}$, et al: $\mathrm{C} / \mathrm{EBP} \beta$ promotes the viability of human bladder cancer cell by contributing to the transcription of bladder cancer specific lncRNA UCA1. Biochem Biophys Res Commun 506: 674-679, 2018.

35. Wu W, Zhang S, Li X, Xue M, Cao S and Chen W: Ets-2 regulates cell apoptosis via the Akt pathway, through the regulation of urothelial cancer associated 1, a long non-coding RNA, in bladder cancer cells. PLoS One 8: e73920, 2013.

36. Wang ZQ, Cai Q, Hu L, He CY, Li JF, Quan ZW, Liu BY, Li C and Zhu ZG: Long noncoding RNA UCA1 induced by SP1 promotes cell proliferation via recruiting EZH2 and activating AKT pathway in gastric cancer. Cell Death Dis 8: e2839, 2017. 
37. Cui X, Zhao C, Yao X, Qian B, Su C, Ren Y, Yao Z, Gao X and Yang J: SND1 acts as an anti-apoptotic factor via regulating the expression of lncRNA UCA1 in hepatocellular carcinoma. RNA Biol 15: 1364-1375, 2018.

38. Su Y, Zhou Y, Sun YJ, Wang YL, Yin JY, Huang YJ, Zhang JJ, He AN, Han K, Zhang HZ, et al: Macrophage-derived CCL18 promotes osteosarcoma proliferation and migration by upregulating the expression of UCA1. J Mol Med (Berl) 97: 49-61, 2019.

39. Bourguignon LYW: Matrix hyaluronan-CD44 interaction activates MicroRNA and LncRNA Signaling Associated With chemoresistance, invasion, and tumor progression. Front Oncol 9: 492, 2019.

40. Hung YP, Redig A, Hornick JL and Sholl LM: ARID1A mutations and expression loss in non-small cell lung carcinomas: Clinicopathologic and molecular analysis. Mod Pathol 33: 2256-2268, 2020.

41. Wang T, Gao X, Zhou K, Jiang T, Gao S, Liu P, Zuo X and Shi X Role of ARID1A in epithelial-mesenchymal transition in breast cancer and its effect on cell sensitivity to 5-FU. Int J Mol Med 46: $1683-1694,2020$

42. Ferri-Borgogno S, Barui S, McGee AM, Griffiths T, Singh PK, Piett CG, Ghosh B, Bhattacharyya S, Singhi A, Pradhan K, et al Paradoxical Role of AT-rich interactive domain 1a in restraining pancreatic carcinogenesis. Cancers (Basel) 12: 2695, 2020.

43. Kumar PP, Emechebe U, Smith R, Franklin S, Moore B Yandell M, Lessnick SL and Moon AM: Coordinated control of senescence by lncRNA and a novel T-box 3 co-repressor complex. Elife 3: e02805, 2014

44. Huang J, Zhou N, Watabe K, Lu Z, Wu F, Xu M and Mo YY: Long non-coding RNA UCA1 promotes breast tumor growth by suppression of p27 (Kip1). Cell Death Dis 5: e1008, 2014.

45. Zhou Y, Meng X, Chen S, Li W, Li D, Singer R and Gu W: IMP1 regulates UCA1-mediated cell invasion through facilitating UCA1 decay and decreasing the sponge effect of UCA1 for miR-122-5p. Breast Cancer Res 20: 32, 2018.

46. Zhang TH, Liang LZ, Liu XL, Wu JN, Su K, Chen JY and Zheng QY: LncRNA UCA1/miR-124 axis modulates TGF $\beta 1$-induced epithelial-mesenchymal transition and invasion of tongue cancer cells through JAG1/Notch signaling. J Cell Biochem 120: 10495-10504, 2019.

47. Hiemer SE, Szymaniak AD and Varelas X: The transcriptional regulators TAZ and YAP direct transforming growth factor beta-induced tumorigenic phenotypes in breast cancer cells J Biol Chem 289: 13461-13474, 2014.

48. Guo J, Li Y, Duan H and Yuan L: Metformin suppresses the proliferation and promotes the apoptosis of colon cancer cells through inhibiting the expression of long noncoding RNA-UCA1. Onco Targets Ther 13: 4169-4181, 2020.

49. Li T, Sun X and Jiang X: UCA1 involved in the metforminregulated bladder cancer cell proliferation and glycolysis. Tumour Biol 39: 1010428317710823, 2017.

50. Guo M, Zhou JJ and Huang W: Metformin alleviates endometrial hyperplasia through the UCA1/miR144/TGFbeta1/AKT signaling pathway. Int J Mol Med 45: 623-633, 2020.

51. Ding Y, Yuan X, Gu W and Lu L: Treatment with metformin prevents pre-eclampsia by suppressing migration of trophoblast cells via modulating the signaling pathway of UCA1/miR-204/ MMP-9. Biochem Biophys Res Commun 520: 115-121, 2019.

52. Zha Z, Han Q, Liu W and Huo S: IncRNA GAS8-AS1 downregulates lncRNA UCA1 to inhibit osteosarcoma cell migration and invasion. J Orthop Surg Res 15: 38, 2020.

53. Zhou Y, Li Y, Wang N, Li X, Zheng J and Ge L: UPF1 inhibits the hepatocellular carcinoma progression by targeting long non-coding RNA UCA1. Sci Rep 9: 6652, 2019.

54. Pan J, Dai Q, Zhang T and Li C: Palmitate acid promotes gastric cancer metastasis via FABP5/SP1/UCA1 pathway. Cancer Cell Int 19: 69, 2019.

55. Jahangiri B, Khalaj-Kondori M, Asadollahi E and Sadeghizadeh M: Cancer-associated fibroblasts enhance cell proliferation and metastasis of colorectal cancer SW480 cells by provoking long noncoding RNA UCA1. J Cell Commun Signal 13: 53-64, 2019.

56. Hu JJ, Song W, Zhang SD, Shen XH, Qiu XM, Wu HZ, Gong PH, Lu S, Zhao ZJ, He ML and Fan H: HBx-upregulated lncRNA UCA1 promotes cell growth and tumorigenesis by recruiting EZH2 and repressing p27Kip1/CDK2 signaling. Sci Rep 6: 23521, 2016.

57. Lv S, Yuan P, Lu C, Dong J, Li M, Qu F, Zhu Y and Zhang J: QiShenYiQi pill activates autophagy to attenuate reactive myocardial fibrosis via the PI3K/AKT/mTOR pathway. Aging (Albany NY): Feb 11, 2021 (Epub ahead of print). doi: 10.18632/ aging.202482.
58. Zhou S, Zhu Y,Li Z,Zhu Y,He Z and Zhang C: Exosome-derived long non-coding RNA ADAMTS9-AS2 suppresses progression of oral submucous fibrosis via AKT signalling pathway. J Cell Mol Med 25: 2262-2273, 2021

59. Goyal B, Yadav SRM, Awasthee N, Gupta S, Kunnumakkara AB and Gupta SC: Diagnostic, prognostic, and therapeutic significance of long non-coding RNA MALAT1 in cancer. Biochim Biophys Acta Rev Cancer 1875: 188502, 2021.

60. Ghafouri-Fard S, Abak A, Tondro Anamag F, Shoorei H, Majidpoor $\mathrm{J}$ and Taheri M: The emerging role of non-coding RNAs in the regulation of PI3K/AKT pathway in the carcinogenesis process. Biomed Pharmacother 137: 111279, 2021.

61. Xin H, Liu N, Xu X, Zhang J, Li Y, Ma Y, Li G and Liang J: Knockdown of lncRNA-UCA1 inhibits cell viability and migration of human glioma cells by miR-193a-mediated downregulation of CDK6. J Cell Biochem 120: 15157-15169, 2019.

62. Sun MD, Zheng YQ, Wang LP, Zhao HT and Yang S: Long noncoding RNA UCA1 promotes cell proliferation, migration and invasion of human leukemia cells via sponging miR-126. Eur Rev Med Pharmacol Sci 22: 2233-2245, 2018.

63. Sun S, Wu Y, Guo W, Yu F, Kong L, Ren Y, Wang Y, Yao X, Jing C, Zhang C, et al: STAT3/HOTAIR signaling axis regulates HNSCC growth in an EZH2-dependent manner. Clin Cancer Res 24: 2665-2677, 2018.

64. Yang R, Wang M, Zhang G, Bao Y, Wu Y, Li X, Yang W and Cui H: E2F7-EZH2 axis regulates PTEN/AKT/mTOR signalling and glioblastoma progression. Br J Cancer 123: 1445-1455, 2020.

65. Han H, Wang S, Meng J, Lyu G, Ding G, Hu Y, Wang L, Wu L, Yang W, Lv Y, et al: Long noncoding RNA PART1 restrains aggressive gastric cancer through the epigenetic silencing of PDGFB via the PLZF-mediated recruitment of EZH2. Oncogene 39: 6513-6528, 2020.

66. Cha TL, Zhou BP, Xia W, Wu Y, Yang CC, Chen CT, Ping B, Otte AP and Hung MC: Akt-mediated phosphorylation of EZH2 suppresses methylation of lysine 27 in histone H3. Science 310: 306-310, 2005

67. Chen P, Wan D, Zheng D, Zheng Q, Wu F and Zhi Q: Long non-coding RNA UCA1 promotes the tumorigenesis in pancreatic cancer. Biomed Pharmacother 83: 1220-1226, 2016.

68. Yang C, Li X, Wang Y, Zhao L and Chen W: Long non-coding RNA UCA1 regulated cell cycle distribution via CREB through PI3-K dependent pathway in bladder carcinoma cells. Gene 496: $8-16,2012$

69. Wang X, Gong Y, Jin B, Wu C, Yang J, Wang L, Zhang Z and Mao Z: Long non-coding RNA urothelial carcinoma associated 1 induces cell replication by inhibiting BRG1 in 5637 cells. Oncol Rep 32: 1281-1290, 2014.

70. Pan J, Li X, Wu W, Xue M, Hou H, Zhai W and Chen W: Long non-coding RNA UCA1 promotes cisplatin/gemcitabine resistance through CREB modulating miR-196a-5p in bladder cancer cells. Cancer Lett 382: 64-76, 2016.

71. Li T, Xiao Y and Huang T: HIF1- $\alpha$-ainduced upregulation of lncRNA UCA1 promotes cell growth in osteosarcoma by inactivating the PTEN/AKT signaling pathway. Oncol Rep 39: 1072-1080, 2018.

72. Ma H, Su R, Feng H, Guo Y and Su G: Long noncoding RNA UCA1 promotes osteosarcoma metastasis through CREB1-mediated epithelial-mesenchymal transition and activating PI3K/AKT/mTOR pathway. J Bone Oncol 16: 100228, 2019.

73. Wu ZR, Yan L, Liu YT, Cao L, Guo YH, Zhang Y, Yao H, Cai L, Shang HB, Rui WW, et al: Inhibition of mTORC1 by lncRNA H19 via disrupting 4E-BP1/Raptor interaction in pituitary tumours. Nat Commun 9: 4624, 2018.

74. Wu C and Luo J: Long non-coding RNA (lncRNA) urothelial carcinoma-associated 1 (UCA1) enhances tamoxifen resistance in breast cancer cells via inhibiting mTOR signaling pathway. Med Sci Monit 22: 3860-3867, 2016.

75. Popova NV and Jücker M: The Role of mTOR Signaling as a Therapeutic Target in Cancer. Int J Mol Sci 22: 1743, 2021.

76. Zhang Z, Li H, Cui Z, Zhou Z, Chen S, Ma J, Hou L, Pan X and Li Q: Long non-coding RNA UCA1 relieves cardiomyocytes H9c2 injury aroused by oxygen-glucose deprivation via declining miR-122. Artif Cells Nanomed Biotechnol 47: 3492-3499, 2019.

77. Wang QS, Zhou J and Li X: LncRNA UCA1 protects cardiomyocytes against hypoxia/reoxygenation induced apoptosis through inhibiting miR-143/MDM2/p53 axis. Genomics 112: $574-580,2020$

78. Zhang J and Zhang C: Silence of long non-coding RNA UCA1 inhibits hemangioma cells growth, migration and invasion by up-regulation of miR-200c. Life Sci 226: 33-46, 2019. 
79. Li Z, Li X, Wu S, Xue M and Chen W: Long non-coding RNA UCA1 promotes glycolysis by upregulating hexokinase 2 through the mTOR-STAT3/microRNA143 pathway. Cancer Sci 105: 951-955, 2014

80. van Andel H, Kocemba KA, Spaargaren M and Pals ST: Aberrant Wnt signaling in multiple myeloma: molecular mechanisms and targeting options. Leukemia 33: 1063-1075, 2019.

81. Zhang B, Fang S, Cheng Y, Zhou C and Deng F: The long non-coding RNA, urothelial carcinoma associated 1, promotes cell growth, invasion, migration, and chemo-resistance in glioma through $\mathrm{Wnt} / \beta$-catenin signaling pathway. Aging (Albany NY) 11: 8239-8253, 2019.

82.Lu HW and Liu XD: UCA1 promotes papillary thyroid carcinoma development by stimulating cell proliferation via Wnt pathway. Eur Rev Med Pharmacol Sci 22: 5576-5582, 2018.

83. Liu H, Wang G, Yang L, Qu J, Yang Z and Zhou X: Knockdown of long non-coding RNA UCA1 increases the tamoxifen sensitivity of breast cancer cells through inhibition of Wnt $/ \beta$-Catenin Pathway. PLoS One 11: e0168406, 2016.

84. Chen X, Gao J, Yu Y, Zhao Z and Pan Y: Long non-coding RNA UCA1 targets miR-185-5p and regulates cell mobility by affecting epithelial-mesenchymal transition in melanoma via Wnt/3-catenin signaling pathway. Gene 676: 298-305, 2018.

85. Zhu G, Liu X, Su Y, Kong F, Hong X and Lin Z: Knockdown of urothelial carcinoma-associated 1 suppressed cell growth and migration through regulating miR-301a and CXCR4 in osteosarcoma MHCC97 Cells. Oncol Res 27: 55-64, 2018.

86. Chen T, Chen Z, Lian X, Wu W, Chu L, Zhang S and Wang L: MUC 15 promotes osteosarcoma cell proliferation, migration and invasion through livin, MMP-2/MMP-9 and Wnt/ $\beta$-catenin signal pathway. J Cancer 12: 467-473, 2021.

87. Gui X, Li H, Li T, Pu H and Lu D: Long Noncoding RNA CUDR regulates HULC and $\beta$-catenin to govern human liver stem cell malignant differentiation. Mol Ther 23: 1843-1853, 2015.

88. Lombard DB, Cierpicki T and Grembecka J: Combined MAPK Pathway and HDAC Inhibition Breaks Melanoma. Cancer Discov 9: 469-471, 2019

89. Kong L, Wu Q, Zhao L, Ye J, Li N and Yang H: Upregulated lncRNA-UCA1 contributes to metastasis of bile duct carcinoma through regulation of miR-122/CLIC1 and activation of the ERK/MAPK signaling pathway. Cell Cycle 18: 1212-1228, 2019.

90.Li D, Hao S and Zhang J: Long non-coding RNA UCA1 exerts growth modulation by miR-15a in human thyroid cancer TPC-1 cells. Artif Cells Nanomed Biotechnol 47: 1815-1822, 2019.

91. Nixon CC, Mavigner M, Sampey GC, Brooks AD, Spagnuolo RA Irlbeck DM, Mattingly C, Ho PT, Schoof N, Cammon CG, et al Systemic HIV and SIV latency reversal via non-canonical NF- $\kappa$ B signalling in vivo. Nature 578: 160-165, 2020

92.Zheng Q, Lin Z, Li X, Xin X, Wu M, An J, Gui X, Li T, Pu H, $\mathrm{Li} \mathrm{H}$ and Lu D: Inflammatory cytokine IL6 cooperates with CUDR to aggravate hepatocyte-like stem cells malignant transformation through NF- $\mathrm{B}$ signaling. Sci Rep 6: 36843, 2016.

93. Yu Q, Zhao MW and Yang P: LncRNA UCA1 suppresses the inflammation via modulating miR-203-mediated regulation of MEF2C/NF- $\kappa \mathrm{B}$ signaling pathway in epilepsy. Neurochem Res 45: 783-795, 2020.

94. Qin L, Jia Z, Xie D and Liu Z: Knockdown of long noncoding RNA urothelial carcinoma-associated 1 inhibits cell viability, migration, and invasion by regulating microRNA-182 in gastric carcinoma. J Cell Biochem 119: 10075-10086, 2018.

95. de Bock CE, Demeyer S, Degryse S, Verbeke D, Sweron B, Gielen O, Vandepoel R, Vicente C, Vanden Bempt M, Dagklis A, et al: HOXA9 cooperates with activated JAK/STAT signaling to drive leukemia development. Cancer Discov 8: 616-631, 2018

96. Jiang H, Zhu M, Wang H and Liu H: Suppression of lncRNA MALAT1 reduces pro-inflammatory cytokines production by regulating miR-150-5p/ZBTB4 axis through JAK/STAT signal pathway in systemic juvenile idiopathic arthritis. Cytokine 138 $155397,2021$.

97. Yang W, Qian Y, Gao K, Zheng W, Wu G, He Q, Chen Q, Song Y, Wang L, Wang Y, et al: LncRNA BRCAT54 inhibits the tumorigenesis of non-small cell lung cancer by binding to RPS9 to transcriptionally regulate JAK-STAT and calcium pathway genes. Carcinogenesis 42: 80-92, 2021

98. Li JL, Liu XL, Guo SF, Yang Y, Zhu YL and Li JZ: Long noncoding RNA UCA1 regulates proliferation and apoptosis in multiple myeloma by targeting miR-331-3p/IL6R axis for the activation of JAK2/STAT3 pathway. Eur Rev Med Pharmacol Sci 23: 9238-9250, 2019
99. Liu J, Luo C, Zhang C, Cai Q, Lin J, Zhu T and Huang X Upregulated lncRNA UCA1 inhibits trophoblast cell invasion and proliferation by downregulating JAK2. J Cell Physiol 235 7410-7419, 2020

100. Wang H, Yao G, Li L, Ma Z, Chen J and Chen W: LncRNA-UCA1 inhibits the astrocyte activation in the temporal lobe epilepsy via regulating the JAK/STAT signaling pathway. J Cel Biochem 121: 4261-4270, 2020.

101. Xu J, Shao T, Song M, Xie Y, Zhou J, Yin J, Ding N, Zou H, $\mathrm{Li} \mathrm{Y}$ and Zhang J: MIR22HG acts as a tumor suppressor via TGF $\beta / S M A D$ signaling and facilitates immunotherapy in colorectal cancer. Mol Cancer 19: 51, 2020.

102. Zhang ZS, Wang J, Zhu BQ and Ge L: Long noncoding RNA UCA1 promotes multiple myeloma cell growth by targeting TGF-beta. Eur Rev Med Pharmacol Sci 22: 1374-1379, 2018

103. Shu T, He L, Wang X, Pang M, Yang B, Feng F, Wu Z, Liu C, Zhang S, Liu B, et al: Long noncoding RNA UCA1 promotes chondrogenic differentiation of human bone marrow mesenchymal stem cells via miRNA-145-5p/SMAD5 and miRNA-124-3p/SMAD4 axis. Biochem Biophys Res Commun 514: 316-322, 2019.

104. Li Z, Liu H, Zhong Q, Wu J and Tang Z: LncRNA UCA1 is necessary for TGF- $\beta$-induced epithelial-mesenchymal transition and stemness via acting as a ceRNA for Slug in glioma cells. FEBS Open Bio 8: 1855-1865, 2018

105. Zhang M, Zhao Y, Zhang Y, Wang D, Gu S, Feng W, Peng W, Gong $\mathrm{A}$ and $\mathrm{Xu}$ M: LncRNA UCA1 promotes migration and invasion in pancreatic cancer cells via the Hippo pathway. Biochim Biophys Acta Mol Basis Dis 1864: 1770-1782, 2018

106. Tian Y, Zhang X, Hao Y, Fang Z and He Y: Potential roles of abnormally expressed long noncoding RNA UCA1 and Malat-1 in metastasis of melanoma. Melanoma Res 24: 335-341, 2014.

107. Liu Q, Li Y, Lv W, Zhang G, Tian X, Li X, Cheng H and Zhu C: UCA1 promotes cell proliferation and invasion and inhibits apoptosis through regulation of the miR129-SOX4 pathway in renal cell carcinoma. Onco Targets Ther 11: 2475-2487, 2018.

108. Duan Q, Xu M, Wu M, Zhang X, Gan M and Jiang H: Long noncoding RNA UCA1 promotes cell growth, migration, and invasion by targeting miR-143-3p in oral squamous cell carcinoma. Cancer Med 9: 3115-3129, 2020.

109. Li ZG, Xiang WC, Shui SF, Han XW, Guo D and Yan L: 11 Long noncoding RNA UCA1 functions as miR-135a sponge to promote the epithelial to mesenchymal transition in glioma. J Cell Biochem 121: 2447-2457, 2020

110. Sun S, Gong C and Yuan K: LncRNA UCA1 promotes cell proliferation, invasion and migration of laryngeal squamous cell carcinoma cells by activating Wnt/ $\beta$-catenin signaling pathway. Exp Ther Med 17: 1182-1189, 2019.

111. Chen X, Wang Z, Tong F, Dong X, Wu G and Zhang R: IncRNA UCA1 Promotes Gefitinib Resistance as a ceRNA to Target FOSL2 by Sponging miR-143 in Non-small Cell Lung Cancer. Mol Ther Nucleic Acids 19: 643-653, 2020.

112. He C, Lu X, Yang F, Qin L, Guo Z, Sun Y and Wu J: LncRNA UCA1 acts as a sponge of miR-204 to up-regulate CXCR4 expression and promote prostate cancer progression. Biosci Rep 39: BSR20181465, 2019.

113. Han R, Chen S, Wang J, Zhao Y and Li G: LncRNA UCA1 affects epithelial-mesenchymal transition, invasion, migration and apoptosis of nasopharyngeal carcinoma cells. Cell Cycle 18: 3044-3053, 2019.

114. Yu Y, Gao F, He Q, Li G and Ding G: lncRNA UCA1 functions as a ceRNA to promote prostate cancer progression via sponging miR143. Mol Ther Nucleic Acids 19: 751-758, 2020.

115. Gharib E, Anaraki F, Baghdar K, Ghavidel P, Sadeghi H, Nasrabadi PN, Peyravian N, Aghdaei HA, Zali MR and Mojarad EN: Investigating the diagnostic performance of HOTTIP, PVT1, and UCA1 long noncoding RNAs as a predictive panel for the screening of colorectal cancer patients with lymph node metastasis. J Cell Biochem 120: 14780-14790, 2019.

116. Esfandi F, Taheri M, Kholghi Oskooei V and Ghafouri-Fard S Long noncoding RNAs expression in gastric cancer. J Cell Biochem 120: 13802-13809, 2019.

117. Pan J, Xie X, Li H, Li Z, Ren C and Ming L: Detection of serum long non-coding RNA UCA1 and circular RNAs for the diagnosis of bladder cancer and prediction of recurrence. Int J Clin Exp Pathol 12: 2951-2958, 2019.

118. Hu ML, Wang XY and Chen WM: TGF- $\beta 1$ upregulates the expression of 1ncRNA UCA1 and its downstream HXK2 to promote the growth of hepatocellular carcinoma. Eur Rev Med Pharmacol Sci 22: 4846-4854, 2018. 
119. Zheng ZK, Pang C, Yang Y, Duan Q, Zhang J and Liu WC: Serum long noncoding RNA urothelial carcinoma-associated 1: A novel biomarker for diagnosis and prognosis of hepatocellular carcinoma. J Int Med Res 46: 348-356, 2018.

120. Mirzajani S, Ghafouri-Fard S, Habibabadi JM, Arsang-Jang S, Omrani MD, Fesharaki SSH, Sayad A and Taheri M: Expression analysis of lncRNAs in refractory and non-refractory epileptic patients. J Mol Neurosci 70: 689-698, 2020.

121. Yu X, Wang R, Han C, Wang Z and Jin X: A panel of urinary long non-coding RNAs differentiate bladder cancer from urocystitis. J Cancer 11: 781-787, 2020.

122. Mahvi DA, Liu R, Grinstaff MW, Colson YL and Raut CP: Local cancer recurrence: The realities, challenges, and opportunities for new therapies. CA Cancer J Clin 68: 488-505, 2018.

123. Yao F, Wang Q and Wu Q: The prognostic value and mechanisms of lncRNA UCA1 in human cancer. Cancer Manag Res 11: 7685-7696, 2019.

124. Guo N, Sun Q, Fu D and Zhang Y: Long non-coding RNA UCA1 promoted the growth of adrenocortical cancer cells via modulating the miR-298-CDK6 axis. Gene 703: 26-34, 2019.

125. Kang K, Huang YH, Li HP and Guo SM: Expression of UCA1 and MALAT1 long-chain non-coding RNAs in esophageal squamous cell carcinoma tissues is predictive of patient prognosis. Arch Med Sci 14: 752-759, 2018.

126. Tang X, Yu L, Bao J, Jiang P and Yan F: Function of long noncoding RNA UCA1 on gastric cancer cells and its clinicopathological significance in plasma. Clin Lab: Nov 1, 2019 (Epub ahead of print). doi: 10.7754/Clin.Lab.2019.181233.

127. Yang L, Zhang L, Lu L and Wang Y: lncRNA UCAl increases proliferation and multidrug resistance of retinoblastoma cells through downregulating miR-513a-5p. DNA Cell Biol 39: 69-77, 2020.

128. Wang J, Ye C, Liu J and Hu Y: UCA1 confers paclitaxel resistance to ovarian cancer through miR-129/ABCB1 axis. Biochem Biophys Res Commun 501: 1034-1040, 2018.

129. Zhang Y, Liu Y and Xu X: Knockdown of LncRNA-UCA1 suppresses chemoresistance of pediatric AML by inhibiting glycolysis through the microRNA-125a/hexokinase 2 pathway. J Cell Biochem 119: 6296-6308, 2018.
130. Yang YN, Zhang R, Du JW, Yuan HH, Li YJ, Wei XL, Du XX, Jiang SL and Han Y: Predictive role of UCA1-containing exosomes in cetuximab-resistant colorectal cancer. Cancer Cell Int 18: 164, 2018.

131. Zhu HY, Bai WD, Ye XM, Yang AG and Jia LT: Long non-coding RNA UCA1 desensitizes breast cancer cells to trastuzumab by impeding miR-18a repression of Yes-associated protein 1 . Biochem Biophys Res Commun 496: 1308-1313, 2018.

132. Xiao Y, Jiao C, Lin Y, Chen M, Zhang J, Wang J and Zhang Z: lncRNA UCA1 contributes to imatinib resistance by acting as a ceRNA against miR-16 in chronic myeloid leukemia cells. DNA Cell Biol 36: 18-25, 2017.

133. Wang X, Yang B and Ma B: The UCA1/miR-204/Sirt1 axis modulates docetaxel sensitivity of prostate cancer cells. Cancer Chemother Pharmacol 78: 1025-1031, 2016.

134. Zhen S, Lu J, Chen W, Zhao L and Li X: Synergistic antitumor effect on bladder cancer by rational combination of programmed cell death 1 blockade and CRISPR-Cas9-mediated long non-coding RNA urothelial carcinoma associated 1 knockout. Hum Gene Ther 29: 1352-1363, 2018.

135. Misale S, Yaeger R, Hobor S, Scala E, Janakiraman M, Liska D, Valtorta E, Schiavo R, Buscarino M, Siravegna G, et al: Emergence of KRAS mutations and acquired resistance to anti-EGFR therapy in colorectal cancer. Nature 486: 532-536, 2012.

136. Liang F, Ren C, Wang J, Wang S, Yang L, Han X, Chen Y, Tong G and Yang G: The crosstalk between STAT3 and p53/RAS signaling controls cancer cell metastasis and cisplatin resistance via the Slug/MAPK/PI3K/AKT-mediated regulation of EMT and autophagy. Oncogenesis 8: 59, 2019.

This work is licensed under a Creative Commons Attribution 4.0 International (CC BY 4.0) License. 